\title{
Conflictos sociotemitoriales: la pesca artesanal como bien común en Península Valdés, Argentina
}

\author{
Pía Valeria Rius \\ Universidad Nacional de la Patagonia San Juan Bosco, Comodoro Rivadavia, Argentina. \\ Email: piavrius@gmail.com \\ Lorena V. Alvarez Manníquez \\ CONICET, Universidad Tecnológica Nacional, Puerto Madryn, Argentina. \\ Email: lorenavalva rezm@gmail.com
}

Recibido: 03.07.20 | Aceptado: 07.08.20

Resumen: El artíc ulo estudia la partic ipación de los pescadores artesa na les en la organización de su actividad y los conflictos sociotemitoria les que surgen en la gestión de un bien común y la organización del temitorio. A partir de un trabajo etnográfico, observación direc ta, entrevista sy estud io de doc umentos, se a na liza ron diferentes dispositivospa rtic ipa tivos, que dan cuenta que los pescadores lograron introducir reglamentaciones sobrepasando principios utilitaristas y a segurando la sustentabilidad del recurso pesquero. La dimensión pública de los espacios institucionales permite abordar el status de la pesca artesanal y mostra rel rec onoc imiento existente ha cia los pesca dores como interloc utores válidos, aunque sometido a tensiones. Los resulta dos de los procesos participativos han genera do heramientas y capacidades en tomo a la pesqueńa como bien común, a unque la coexistencia de actividades forma les e informales, prácticas de privatiza ción del teritorio y competencia de actividades socava la legitimidad de la pesca como un bien común temitorial. Palabras clave: Conflictos socioterritoriales; debate públic o; bienes comunes; pesca artesanal; etnografía.

\section{Socio-tenitorial conflic ts: artisanal fishing as a common good in the Valdés Peninsula, Argentina}

\begin{abstract}
The article studies the participation of artisanal fishemen in the organization of their activity and the socio-teritorial conflic ts that arise in the management of a common good and the organization of the teritory. Based on ethnographic work, direct observation, interviews and study of doc uments, different pa rtic ipa to ry mechanisms were ana lyzed, which show that the fishemen managed to introduce regulations that went beyond utilitarian principles and ensured the sustainability of the fishing resource. The public dimension of the institutional spaces allows to address the sta tus of a rtisanal fishing and to show the existing recognition of the fishemen as valid interloc utors, even though they a re subject to tensions. The resultsof the partic ipatory processes have genera ted toolsand capacitiesa round fishing as a common good, although the coexistence of formal and informal activities, temitorial privatization practic es and competition of a c tivities und emmines the leg itimacy of fishing as a teritorial common good.
\end{abstract}

Key words: Socio-teritorial conflict; public debate; common goods; artisanal fishing; ethnography. 


\section{Confilitos sócio-temitoriais: a pesca artesanal como bem comum na Península Valdés, Argentina}

Resumo: O presente artigo estuda a partic ipa ção dospesc adoresa rtesa na isna orga niza ção de sua sa tividadese os c onflitos sóc io-temitoria is que surgem na gestão de um bem comum e na organização do temitório. A partir de um trabalho etnográfico, observação direta, entrevista se estud o de documentos, foram a na lisa dos diferentes dispositivos pa ric ipa tivos, que mostram como ospesc ad oresconseguira m intro duzir regula mentos que ultra passa vam os princípios utilitánios e garantiam a sustentabilidade do recurso pesqueiro. A dimensão públic a dosespaços instituciona is pemite abordaro sta tus da pesca a rtesanal e mostra ro reconhec imento existente dos pescadores como interloc utores válidos, embora sujeitos a tensões. Os resultados dos processos partic ipativos geraram ferramentas e capacidades em tomo da pesca como um bem comum, embora a coexistência de atividadesforma ise informais, práticas de privatização teritorial e competição de atividades prejudique a legitimidade da pesca como um bem comum teritorial.

Palavras-Chave: Conflitos sóc io-teritoria is; debate públic o; bens comuns; pesca artesanal; etnografia.

\section{Como citar este artículo:}

Ruis, P y Alvarez Manríquez, L. (2020). Conflictos so ciotemitoria les: la pesca a rtesanal como bien común en Península Va ldés, Argentina. Polis Revista Latinoamericana, (57), 92-114. doi: http://dx.doi.org/10.32735/S0718-6568/2020-N57-1566

\section{Introducción}

En este artículo exploramos distintos dispositivos instituciona les participativos de elaboración de nomativas y diseño de políticas de desarrollo en tomo a la pesca artesanal que permiten a na lizar en el debate públic o su reconoc imiento como bien común y los procesos de institucionalización a los que dan lugar. Pescadores artesanales en sus espacios a sociativos, funciona rios públicos y científic os confluyen en el debate en tomo a la construcción de prácticas sustentables. Se trata de espacios institucionales en los cuales los propios pesc a dores artesa na les intervienen de manera activa y proponen instrumentos de manejo de la actividad. Los procesos partic ipativos han sido a nalizados para dar cuenta de sus alc ances en trabajos a nteriores a quí pondremos de relieve las modalidades de debate observadas y los principios sobre loscuales se a poyan ${ }^{1}$.

La dimensión temitorial de la economía solidaria considera a los comportamientos de los seres humanos, como una forma de vida que incorpora los conceptos de comunidad y sociedad como componentes del temitorio, «una categońa abarcadora y abarcada, donde procesosnatura lesy socia lesse interpenetran.»(Coraggio, 2011, p. 281). La relación entre esosprocesosa dquiere distinta sformasa lo la rgo del tiempo. Sin embargo, la instituciona lidad

\footnotetext{
'La designación en términos de dispositivos institucionales es amplia ya que se incluyen interacciones entre los distintos actores involucrados acorde con el concepto de procesos de institucionalización orientado a captar relaciones cambiantes. En particular aportamos nuestra reflexión en tomo a la formulación del Plan de Manejo de Península Valdés, la Mesa Técnica Zona 1 y el Cluster de pesca artesanal y maricultura de Península Valdés, así como las prácticas temitoriales a las que dan lugar.
} 
suele serca racteriza da de manera estátic a, a partirde regula rida descomo un esta do de cosas alcanzado, un orden establecido renuente al estudio de los procesos de institucionalización (Guéry, 2003, Toumey, 2011). El a ná lisisnoma tivo se ve esc ind ido de lastensionesy debatesque participan de esos procesos de instituciona lización. El problema señala do por Toumey sugiere que la emergencia de una declaración de un temitorio como área natural protegida, o las nomativas de ordenamiento temitorial, son el resultado de un largo trabajo de producción colectiva, no lineal. Comprender su funcionamiento implica interrogar no sólo la legislación que protege un determinado espacio, como el área natural protegida península Valdés o práctica como la pesca artesanal o la maricultura sino el debate y lasprácticasque la atraviesan, fundamentan su presencia y adquieren o no una legitimidad colectiva.

Boltanski y Thevenot (1991) analizan distintos regímenes de argumentación pública que pueden servir como punto de a poyo tanto para los argumentos enuncia dos en forma crítica como para las justific a ciones desa rrolladas que responden a esas críticas o para sostener un curso de acción ${ }^{2}$. El aporte resulta pertinente ya que realiza una sociología de la crítica y pone de relieve lascaracteństicas de varia dos regímenes y criterios de evaluación que desplazan la validez del criterio mercantil y de la maximiza ción de la ganancia económica como regla última de decisión. Desde estos enfoques se analizan las capacidades para someter a la prueba del debate público distintos principios como la reputación, el interés colectivo o la efic acia. La reflexión a partir de estas referencias en distintos campos de investiga ción extendieron y precisa ron el alcance de la propuesta señalando por ejemplo regímenes domésticos plurales (Thévenot, 2016) o nuevos regímenes a propiados por ejemplo para lascontroversia sa mbienta les (Mathieu, 2011), formas de involucramiento fundadas en el don (Boltanski, 2000) o la definición de bienes comunes en contextos urbanos de acción colectiva (Pattaroni, 2007).El debate público ofrece la posibilidad de recumir a distintos modelos y clarific a r los principios de justic ia sobre los c ua les se a poyan las decisioneso lascríticas. Las expresiones en forma crítica, rea liza das en un espa c io plural, en el que confluyen diversas instituc ionesy representa ntesloc a les, son susc eptibles de teneren cuenta posic ionesa dversas, de busc armoderar losintereses en conflic to a partir de a cuerdossobre los bienescomunes y abandonar la imposición de la voluntad del más fuerte como principio de acción. La pluralidad de manerasque laspersonas someten a prueba losargumentos, ca lific an, se involuc ran y se apropian mediante diferentes registrosde justific a ción, constituyen formas de definic ión de los bienescomunes. La propuesta pemite superarla tensión entre el interés individual y colectivo mediante dispositivos de puesta a prueba pública e introduce una altemativa a la relación de fuerza (Nardacchione, 2003). La institución aparece como una manera de co presencia y coordinación de pruebas sucesivas. Atravesar esaspruebasargumentativas forma parte de lascapacidadesdesa rolladaspor una perso-

\footnotetext{
${ }^{2}$ El modelo denominado de las ciudades se inspira de la filosofía política (Boltanski y Thévenot, 1991). Cada una de las seis polis varían según «as capacidades que los actores ponen en juego cuando tienen que justific ar sus acciones o sus crític as» (ibíd., 26) y las formas del acuerdo entre diferentes actores, apoyadas en los principios de generalidad y de órdenes de valor que permiten dirimir las controversias (Mathieu, 2011). En la ciudad inspirada el modo de evaluación es la gracia y la creatividad; en la doméstica la estima y la reputación; en la cívica el interés colectivo; en la ciudad de la opinión es la reputación frente a la opinión pública; en la ciudad mercantil el precio y la ciudad industrial se rige por la producción y la eficacia.
} 
na que pertenece a una comunidad cultural, profesional, étnica, nacional, etc. La construcción de un «nosotros» supone una perspectiva de lectura colectiva compartida para describ ir y a na liza r la diversidad de las experiencias sensibles individua les en un dispositivo de deliberación pública (Toumey, 2011). Aquí los dispositivos institucionales participativos aparecen como un ámbito que permite indagarhasta qué punto se desa rolla un régimen de acción específic o para los bienes comunes en la pesca artesanal de Península Valdés.

La investigación nos pemitirá dar cuenta de los conflic tos soc ioteritoria les observados en el proceso de decisión entre los distintosa c toresy a na liza r los procesosde instituc iona liza c ión (Toumey, 2011) que van prevaleciendo en distintas etapas a partir de la declaración de la Península Valdéscomo área protegida y Patrimonio de la Humanidad porla UNESCO (1999). El teritorio es sometido a un proceso de regulación creciente que pone en discusión los bienes protegidos por esa condición y en particular el intento por coordinar los distintos saberes para consensuar acciones, a portes técnic os pertinentespara el sector de la pesca a rtesanal. Sin embargo, también se genera una disputa porla preeminencia de deteminadas formas de producción de saber y de signific aciones. Los conflictos sociotemitoriales, liga dos al acceso, conserva ción y control de los recursos naturales, «suponen por parte de los a c tores enfrenta dos, intereses y va lores divergentes en tomo a los mismos", e involuc ran luchasvinculadasa la defensa de ciertostemitoriosy la pertenencia de losindividuos (Sva mpa, 2011). Los documentos que produc en las distintas mesas instituc ionales, proveen justificaciones de las decisiones tomadas, que pemiten explicitar las operaciones a través de las cuales se asientan el fundamento de sus a fima ciones (Boltanski, 1990). En efecto, se registran distintos criterios que permiten legitimar las propuestas que resulta ron de los distintos espacios, de modo de comprender la discusión técnica transdisciplinar de acuerdo a las perspectivas de los propios ac tores y a las condiciones para un desa rrollo sustentable, término empleado por los propios pesca dores a rtesa na les y su entomo. En este sentido, poner el énfasis en procesos de instituc ionaliza ción en curso remite a la posibilidad y la exigencia del carácter público de las decisionesque alcanzan a la actividad, a la necesaria presencia de marcos legales formales que le den sustento y a procesos de gestión acordes a las práctic asconsensuadas.

La gestión temitorial reconoce el marco de nomas e instituciones formales y no formales como elementos claves para pensar en la escala del temitorio, las cuestiones particula res de una unidad temitorial, y por, sobre todo, conceptualizar al teritorio como una construcción social continua que representa el estilo de desa rollo de una sociedad, mediante las actividades que la población practic a sobre el medio físico y las interacciones que se producen entre ellas (Gómez Orea, 2002). La construcción social de la pesca a rtesanal como bien común es un proceso abierto cuyo a ná lisis a porta rá a una mayor comprensión de los procesos de instituc iona liza c ión en c urso y de los conflic tos so c iotemitoria les que lo a tra viesan teniendo en cuenta.

El Plan de manejo de Península Valdés (PM) pone de relieve la complejidad de la gestión del teritorio atravesado por prácticas históricas en disputa por el teritorio. El turismo, la 
ganadería, la pesca artesanal y el desa rollo urbano aparecen como actividades básicas previas, que se intentan amonizar, sin embargo, la normativa no es de fácil acceso y los a gentesa pelan a costumbresy prác ticas previas más a llá de los a cuerdos que esta refleja. La universidad y los organismos productores de conocimiento público legítimo (Gusfield, 2016) que partic ipa ron, c onstituyeron actores centra les en la mediación entre el sector productivo y el gubemamental, a unque este último también se vincula mediante relaciones directasc on lospesc a doresa rtesa na lesobserva das dentro y fuera de lasmesas instituc iona les. Por su parte, los pescadores, en tanto protagonistas de la actividad, dan sentido al proceso e intentan imprimir direc ciones espec íficas, pero no siempre son acorda das por los distintos miembros de ese colectivo heterogéneo. Queda de manifiesto a sí que los bienescomunes son parte de un proceso continuo de luchas, negociaciones y redefiniciones políticas entre diferentes grupos de actores (Vercelli y Thomas, 2008).

El a nálisis in situ de las playas y sus accesos (Mańn et al., 2017, Álva rez Ma nńquez, 2018) da cuenta de procesos de privatiza ción del teritorio que impiden el cabal funcionamiento del PM y una tendencia al cerc a miento de bienesde ca ra c terístic a sc omunita ria s. En oca siones las mesas de diálogo se muestran como un espacio solic itado por las propias a sociaciones de pescadores artesanales que intentan generar mecanismos de sustentabilidad para el desarrollo de la actividad, por ejemplo, la marisquera ${ }^{3}$. Fina Imente, retoma mos la experiencia del Clústerde Pesca Artesa nal y Maricultura Península Valdés(PAyMPV) que promovió la coord ina ción del sec tor priva do junto con el sec tor públic o, la universidad, téc nic osy científic os para esta blecer polític as sectoria les dura deras y consensuadas a partir de un dispositivo de financiamiento intemacional. Losprocedimientospara el desa rollo del c lústerguiaron la discusión del plan de acción a desa rrollary, establecieron o intenta ron establec er, el rol que cada una de laspartesadoptaría en ese proceso. Sin embargo, los técnicos representantes de universidades, centros de investigación y dependencias estatales, cuentan con una relación con lospescadores artesanalesy el entomo que los rodea que precede al c lúster, dando lugar a tensiones entre las prácticas existentes y la metodología del programa de financiamiento, considerada en forma unánime como demasiado ń́gida.

Los vínculos entre los diferentes a c tores en el seno de los distintos dispositivos se dieron en el marco de un proceso de institucionalización que buscó la continuidad de los consensos a corda dos en donde la partic ipa ción de organismos intemac iona les influye en la a dopción de distintos formatos.

\section{E caso de la pesca artesanal en Península Valdés}

La pesquería del Golfo San José está situada dentro del Área Natural Protegida Península Valdés (ANPPV) en la provincia de Chubut, Argentina. Esta península es una reserva Natural Tuństica desde el año 1983. Fue declarada Patrimonio Natural de la Humanidad bajo la categońa X, y clasificada como Área Protegida con Recursos Manejados, correspondiente

\footnotetext{
${ }^{3}$ Marisqueńa por buceo es una de las tres artes de pesca tradicionales de la pesquería del Golfo San José.
} 
a la categońa VI de los lineamientos de la Unión Intemacional para la Conservación de la Natura leza (UICN).

En la misma unidad temitoria I se desarrollan actividades de pesca artesanal, turismo, ganadería y asentamientos humanos.

En la actividad pesquera artesanal, los pescadores se agrupan según la modalidad de pesca, entre ma risqueros, rederos y recolectores (figura 2). Estos grupos presentan ca racteństicas distintivas en cuanto a la complejidad de las prácticas de pesca, a los bienes de capital y al bienestar o seguridad económica que la comercialización de sus capturas les permite tener.

\section{Materialesy métodos}

La pesca artesanal esabordada en este trabajo desde un enfoque etnográfico que conlleva la participación junto con los pescadores artesanales en distintos procesos de decisión de políticas para el sector. Las autoras han contribuido en la formulación de proyectos como observa doraso miembros de grupos téc nic os y registra ron las competencias desplegadas en el contexto de distintos dispositivos instituciona les, en partic ula r por los miembros de lasasociaciones de pescadoresartesanales.

A partir de la observación direc ta de prácticas temitoria lesy sus sentidos se releva ron distintas tensiones en los usos del teritorio que aparece en disputa. Se analizó la nomativa vigente para la sustentabilidad, en particular el PM, un instrumento legal conformado a partir de procesos participativos que fueron reconstituidos a tra vés de informes y del testimonio de distintos participantes (pescadores artesanales, téc nicos, científic os, grupos de productores de distintas actividades desa rrolladas en Península Valdés, autoridades de a plic ación). En particular se analiza, la pesquería del Golfo San J osé y playa La ralde, reconocida espacial y socialmente por las práctic as tra dicionales de pescadores artesanales. Para realizar el relevamiento se utilizó un registro in situ ${ }^{4}$ de la presencia de uso y actividad, a partir de la observación directa con la técnic a de cuenca visual y tomas fotográficas. Se registró la presencia de actores institucionales por presencia física o códigos (cartelería, presencia de vehíc ulos, equiposo infraestructura) a lo largo del borde costero que conforma Playa La rra lde (Álvarez Manríquez, 2018).

El trabajo incluyó 15 entrevistas en profundidad a pescadores artesanales, técnicos gubernamentales e investigadores relacionados a la pesquería y al área protegida Península Valdés. Se estudia ron a c tas (49), doc umentos de trabajo (2) e informesy documentos téc nicos (11) que plasman la participación de distintos actores en espacios institucionales, y permiten a na lizar los procesosy las discusiones en tomo a la actividad, así como documen-

\footnotetext{
${ }^{4}$ El relevamiento se realizó en el mes de marzo del año 2018.
} 
talesde la pesquería y entrevistas de video y radio a pesc a dores que registran susparticipaciones a siduas en la agenda pública. Se incluyeron fuentes periodísticas y declaraciones públicas en las que las distintas posiciones aparecen bajo la forma de interpelación a la opinión públic a y como llamado de a lerta frente a losriesgos de pérdida de la actividad en las nuevas generaciones por el agota miento de los recursos.

La tabla 1 esquematiza la manera en que estos materiales permiten dar cuenta de las distintas va loraciones que a parecen en disputa en el temitorio y mediante los distintos dispositivos institucionales implementados. El reconocimiento de la pesca artesanal como un bien común aparece como una orientación no lineal en tensión con prácticas de privatización del teritorio.

Tabla 1

Tensiones y avances en tomo al proceso de comunalización Fuente: elaboración propia

\begin{tabular}{|c|c|c|c|c|}
\hline & & $\begin{array}{c}\text { Conflic tos socio-te rrito riales } \\
\text { identific ados }\end{array}$ & $\begin{array}{c}\text { Valoraciones hacia la } \\
\text { comunalización }\end{array}$ & Fuente \\
\hline $\begin{array}{l}\text { Modalidades } \\
\text { de } \\
\text { apropiación } \\
\text { existentes }\end{array}$ & $\begin{array}{l}\begin{array}{c}\text { Prác tic as en el } \\
\text { territo rio }\end{array} \\
\text { Desarrolio a partir } \\
\text { de } 1973\end{array}$ & $\begin{array}{l}\text { Formas de privatización del } \\
\text { territorio. } \\
\text { Competencia de actividades. } \\
\text { Pesca sin permiso. } \\
\text { Formas de trabajo precario. } \\
\text { Incumpimiento de pautas formales } \\
\text { de ordenamiento territorial } \\
\text { Debil reconocimiento de ha figura } \\
\text { del pescador. } \\
\text { Debil reconcomiento de la pesca } \\
\text { como actividad económica y } \\
\text { cultural }\end{array}$ & \multirow{4}{*}{$\begin{array}{l}\text { Sustento económico de las } \\
\text { familias. } \\
\text { Resguardo para las generaciones } \\
\text { futuras. } \\
\text { Saber hacer profesional. } \\
\text { Búsque da de condiciones de } \\
\text { trabajo dignas. } \\
\text { Participación activa. } \\
\text { Antigüedad en la práctica } \\
\text { pesquera. } \\
\text { Explotación sustentable evitar la } \\
\text { pesca sin permiso que no cumple } \\
\text { las norma tivas. } \\
\text { Fallan los sistemas de monitoreo, } \\
\text { control y fiscalización. } \\
\text { Búsqueda de consensos con los } \\
\text { pescadores. } \\
\text { Reconocimiento obtenido por este } \\
\text { grupo profesional como agentes } \\
\text { activos. } \\
\text { Valoración de una identidad } \\
\text { connin. } \\
\text { Reconocimiento de las } \\
\text { capacidades de los grupos } \\
\text { asocia tivos. }\end{array}$} & $\begin{array}{l}\text { Informes técnic os } \\
\text { Entrevistas } \\
\text { Trabajo de campo } \\
\text { Articulos } \\
\text { periodisticos } \\
\text { Publicaciones }\end{array}$ \\
\hline \multirow{3}{*}{$\begin{array}{l}\text { Dispositivos } \\
\text { institucionale } \\
\text { s de puesta } \\
\text { a pueba } \\
\text { pública }\end{array}$} & $\begin{array}{l}\text { Plan de Manejo } \\
\text { Periodo: } 1998-2001 \\
\end{array}$ & $\begin{array}{l}\text { Pugna por la participación de los } \\
\text { pescadores en el proceso de } \\
\text { elaboración del plan de } \\
\text { ordenamiento del área. } \\
\text { Reconocimiento de h antigüedad } \\
\text { de la actividad. } \\
\text { Cuidado ypre servación de1 } \\
\text { ambiente yla biodiversidad. } \\
\text { Reconocmiento de los pescadores } \\
\text { y sus familias como actores del } \\
\text { territorio. }\end{array}$ & & $\begin{array}{l}\text { Documentos de } \\
\text { trabajo } \\
\text { Normativas } \\
\text { Entrevistas } \\
\text { Registros de } \\
\text { participación }\end{array}$ \\
\hline & $\begin{array}{l}\text { Mesa Técnica } \\
\text { Perio do: } 2001-2014\end{array}$ & $\begin{array}{l}\text { Manejo de los recursos pesqueros. } \\
\text { Otorgamiento de permisos de } \\
\text { pesca. }\end{array}$ & & $\begin{array}{l}\text { Actas } \\
\text { Documentos } \\
\text { técricos } \\
\text { Entrevistas } \\
\end{array}$ \\
\hline & $\begin{array}{c}\text { Cluster de } \\
\text { Pesca } \\
\text { Perio do: } 2014-2016\end{array}$ & $\begin{array}{l}\text { Pesca sin permiso. } \\
\text { Formas de privatización del } \\
\text { territorio. } \\
\text { Diferencias entres artes de pesca. }\end{array}$ & & $\begin{array}{l}\text { Observación directa } \\
\text { Actas } \\
\text { Documentos de } \\
\text { trabajo }\end{array}$ \\
\hline
\end{tabular}




\section{Resultados}

En 1968 Ga rrett Hardin publicó su teoría sobre la tragedia de loscomunes, exponiendo que los usuarios de un bien común inevitablemente conducen a la destrucción de los recursos de los cuales dependen. Tal como lo detalla Lerch (2008) encontramos antecedentes de estos postulados desde Aristóteles, quien observó un menor cuidado sobre bienes que pertenecían a un mayor número de individuos, hasta autores como Foster Loyd (cita do en Lerch, 2008), quien describió problemasanálogossobre el manejo descuida do de la propiedad común. En ese mismo sentido lo entiende H. Scott Gordon (citado en Lerch, 2008) en su trabajo «The Economic Theory of a Common- Property Resource: The Fishery»en el cual expresa que «everybody's property is nobody's property»(Lerch, 2008, p. 118).

Tres décadas mástarde, Elinor Ostrom (1999) pone en disc usión la teoría de Hardin, presentando resulta dos de estudios donde se evidencian contra puntos a esos postulados, y propone nuevas ideas sobre los problemas y condic iones favorables para la sostenibilidad de los recursos comunes. Las evidencias de numerosos casos de estudio refutaron el declive inminente de los recursos comunesque argumentó Hardin. Esa teoría convencional presentaba a los participantes desvinculados y sin interés en el diseño de sus propios arreglos de gobemanza (Ostrom et al., 1999). Esta autora presenta evidencia empírica sustancial de muchoscasos de bienescomunesdonde losa genteseconómic osse autoorganizan (Ostrom, 2002). Varios son los autores que han argumentado que el escenario trágico no es, en realidad, un bien común, sino que Hardin describe un régimen de acceso abierto no regulado (Bollier, 2008). Desde la perspectiva pragmátic a ya mencionada la instituc ionaliza ción de un bien común a través del debate público pone de relieve las caracteństic as que son valoradas y legitimadas en un contexto dado como común y compartido por una sociedad. «Hablarde losbienescomunesnosayuda a identific aruna amplia clase de recursosen cuyo control y ma nejo la ciuda danía en general o comunida desespec ćfic astienen intereses polític os y morales.» (Bollier, 2008, p. 31). De esta forma se amplía y complejiza el marco de bienes comunes al reconoc erlos inmersos en una serie de relaciones diversas de poder, valores e identidades sociales; ya no solo refinéndose a un sentido natural (o comúnmente llamado recurso natural) sino a un evento social (Helfrich, 2008).

Trabajarsobre losproblemas de lossistemasque involucran dimensionessocia lesy biofíic as de un determinado espacio y tiempo, requiere un estudio integrado de sistemas complejos, multivariables, no lineales, de esc ala cruzada y cambiantes (Ostrom, 2007). Esos sistemas, además, pueden afectary verse afectados por la percepción que de ellos tienen los actores, el entomo social, económico, polític o y ecológico. La pérdida de recursos es un problema de alcance mundial que tiene sus correspondencias en losámbitos locales, por ese motivo es primordial comprender los procesos que mejoran o deterioran los rec ursos naturales ${ }^{5}$, como

\footnotetext{
${ }^{5}$ «Sólo existen recursos naturales, los cuales se administran como propiedad común, pública o privada. O bien, y es justo aquí donde la literatura repetidamente lleva a confusiones, hay recursos para los cuales no se han otorgado derechos de propiedad, siendo ésta una situación de acceso libre para todos (res nullius)» (Bromley, citado por Lerch, 2008).
} 
así también el entramado de relaciones político-sociales que se involucran. Mantener la integridad de los bienescomunes es lo mismo que mantener sus relaciones, valorese identida des socia les (Bollier, 2008).

Los roles, reacciones y decisiones de los actores que se articulan sobre un bien común dan cuenta del estilo de gestión sobre el sistema. Hasta hace poco, la teoría acepta da suponía que los usua rios de los recursos nunca se auto-orga niza ńan para ma ntener sus recursos y que los gobiernos deben imponer soluciones; sin embargo, la investigación transdisc iplinaria ha evidenciado que algunas políticas gubemamentales aceleran la destruc c ión de recursos, mientras que a lgunos usua rios de rec urso s han invertido su tiempo y energía para lograr la sostenibilidad (Ostrom, 2009). Por el contrario, hay vastos ejemplos donde los usuarios coopera ${ }^{6}$ para produc ir beneficios compartidos a largo plazo (Vollan y Ostrom, 2010). El surgimiento de mesas de diálogo que ha atra vesa do la pesquería del Golfo San J osé, da cuenta de las posibilidades de interpelar a las autoridades locales para producir legislación que resguarde los recursos pesqueros y como dispositivo de co-manejo para evitar la radicalización del conflic to mediante medidas como bloqueos de rutas.

Las experiencias de gestión partic ipativa de bienes comunes, a través de herramientas de co-manejo, planes de manejo de áreas, sistemas de derechos de uso territorial (Santa Ana, 2004), van generando antec edentes en los territorios moviliza dos por los propios prota gonistas. Los bienes comunes sostienen y son sostenidos por colectivos humanos situa dos (Lafuente, 2008). Quienes tienen un rol a c tivo conocen a cerc a de sus resulta dos y desafíos, y conforman un reservorio compartido de experienciasque siguiendo la propuesta de Schutz (1987) da sentido y permea lasacciones desa rrolladas como miembros de ese colectivo.

Desde la economía susta ntiva se pone el a cento en los dispositivos polític o-juńd ic os (Ca illé, 2007) que constituyen un soporte para el funcionamiento del mercado, dejando de la do los intercambios basados en relaciones de don y contra-don. Sin embargo, las mesas institucionales ofrecen un espacio de intercambio en tomo a las reglas de juego que no siempre tienen como horizonte el interés personal si no que por su carác ter público y relativamente abierto ponen a prueba distintos principios compartidos en la esfera pública. Bollier (2008) argumenta en su propuesta, que los bienes comunes ha bilita n un tercer espacio para la genera ción de riqueza, que además de diferirc on la acción gubemamental y la competencia de mercado, pone de relieve otro tipo de valor-ecológico, social, democrático, moral, de tradiciones- que otorgan identidad a una comunidad y la ayudan a autogobemarse.

\footnotetext{
${ }^{6}$ Dentro de las condiciones que propician la gestión cooperativa, Vollan (2010) señala en base a un estudio de bienes comunes forestales, el cumplimiento de reglas, el número de cooperadores, la calidad de liderazgo y las inversiones en fiscalización.
} 


\section{Invitados a última hora}

El ente denominado Administra dora del ANPPV, creado en el año 20017, posee las facultades específic as para el ejercicio de la administración y manejo. El instrumento mediante el cual se gestiona el área natural es el PM, resulta do de un proceso participativo con los distintos sec to res involucrados, incorpora la zonific ación como herramienta para el ordenamiento del uso del espacio continental y marino. La zonificación se realizó en base a la gradación de usos que, se considera, puede soportar el área; va desde áreas destinadas a la protección total de los ambientes hasta áreas que permiten una mayor intensidad de usos, en tanto que los mismos sean sostenibles. El PM, en su capítulo II, enuncia las consideraciones genera les que se derivan de la zonificación. Las actividades que se indican para las diferentes zonas, han tenido en cuenta una gradiente de fragilidad de los ambientes ma rinos, costeros y continentales ante las actividades humanas que puedan realizarse o se estén rea lizando (PM, 2001, p. 94).

En 1998 se comenzó a trabajar en un PM en función del documento de lineamientos y recomendaciones para áreas naturales protegidas fomentadas por la Administración de Parques Nacionales de Argentina. Dicho documento bregaba por la mejora de los procesos de planificación y manejo de áreas naturales protegidas, recomendando la implementación de planes de manejo y su revisión cada 5 años. Estas acciones se dieron en un contexto intemacional de valoriza ción de espacios natura les para su conservación y desa rrollo turístico. Las agencias intemacionales recomendaban de forma explícita que los procesos de planific ación del manejo o el manejo en sí mismo contemplaran la participación de todos los sectores involucrados (PM 2001, p. 4-6). De este modo, para su elaboración se aplicaron herramientas de planeamiento estra tégico partic ipa tivo donde se involuc raron 19 instituciones del sec tor privado, sec tor públic o y la sociedad civil. Los pescadores artesa nales partic iparon a través de sus representantes, lo que significó un desafío y una gran inversión de esfuerzos ya que en ese entonces desconocían los términos, los procesos, la documentación de base, las conceptualizaciones que utilizaban desde el sector público. Cada uno de los encuentros demandaba de los pescadores una gran preparación previa (pescador, entrevista personal, 24 de marzo del 2020). Si bien pudieron plantear muchas de sus inquietudes, de las entrevistas surge que su partic ipación fue, en principio, resistida por algunos actores del sector turístico (tanto estatal como privado) y quedaron cuestiones sin resolver. El proceso participativo involucró 69 encuentros, llegando a registrar poco menos de 400 horas de trabajo colaborativo.

\footnotetext{
${ }^{7}$ Decreto 1328/01 del Poder Ejecutivo provincial. En su anexo incorpora el Plan de Manejo.
} 
Tabla 2

Resumen del proceso participativo del Plan de Manejo del Área Natural Protegida Península Valdés

\begin{tabular}{lccc} 
& Reuniones & Horas & $\%$ \\
\cline { 3 - 5 } $\begin{array}{l}\text { Plenarios del Equipo Ejecutivo de } \\
\text { Planeamiento }\end{array}$ & 22 & 99 & $26 \%$ \\
\hline $\begin{array}{l}\text { Componentes del Plan de Manejo } \\
\text { en comisiones }\end{array}$ & & & \\
\hline 1- Caracterización & 19 & 151 & $40 \%$ \\
\hline 2- Objetivos Direccionales & 1 & 4 & $1 \%$ \\
\hline 3- Categoría de Manejo & 3 & 8 & $2 \%$ \\
\hline 4- Zonificación & 13 & 78 & $21 \%$ \\
\hline 5- Persona Jurídica & 11 & 38 & $10 \%$ \\
\hline & 69 & 378 &
\end{tabular}

Fuente: Elaboración propia en base al Plan de Manejo.

Como se observa en la tabla 2, los registros del proceso de elaboración del plan dan cuenta de la rápida resolución en cuanto a los objetivos del PM, y la categoría de manejo ( $1 \%$ y $2 \%$ del tiempo utilizado) lo que podría respondera la necesidad de seguir los linea mientos preestablecidos nacional e intemacionalmente. En efecto, Ostrom (2008) señala que la gobemanza local siempre esparte de las políticas regionales y naciona les y se ve afectada porlas mismas. Se pueden observarta mbién los esfuerzos a plicadosa la zonificación del área, $21 \%$ de las horas de debate repartidas en 13 reuniones. El PM considera que las áreas protegidas de jurisd ic c ión na cio nal co mo provincial constituyen la esencia de la oferta turística, por lo que el ordenamiento es indispensable para que esta actividad no se transforme en su peor enemigo, atentando contra la integridad natural de las mismas (PM, 2001).

Si bien reconoce la necesidad de límites a la actividad turística, la Península Valdés es una resena Natura I Turístic a desde el año 1983 y la Autoridad de Aplicación del Sistema de Conservación Provincial es el Ministerio de Turismo. Como tal dicta la reglamentación complementa ria y a dministra todas las reservas, c on la excepción del Parque Marino Golfo San José, en el cual la administración es compartida con la Secretaría de Pesca de la provincia. 
Figura 1

Niveles nomativos para la pesca artesanal en el Golfo San José

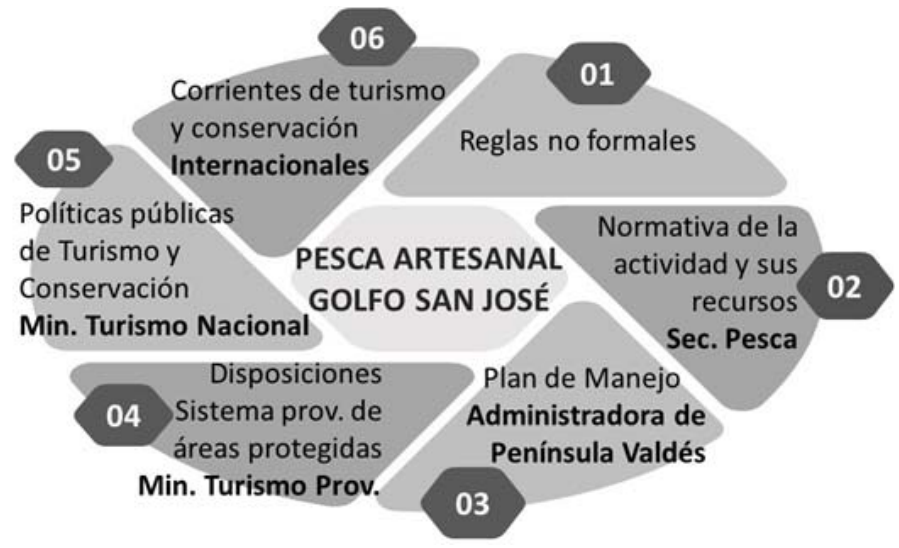

Fuente: Elaboración propia

Si el marco nomativo aparece como argumento propio de las definiciones de la ciudad cívic a (Boltanski y Thévenot, 1991) con la supremacía del bien común, las nomativas provinc ia les surgen vinc ula das a nomas nacionalese intema cionales que delimitan la conformación teritorial y las prácticas sociales. En la figura 1 se puede observar los niveles de nomativos que actúan sobre la unidad teritorial del Golfo San J osé y sobre la actividad de pesc a a rtesanal. Las disposic iones intema ciona lesque se despliega n so bre Península Valdés, condicionan a los subsistemas que la componen, como es la pesqueńa del Golfo San J osé y los pequeños asentamientos costeros, y también potencian la competencia con otras a ctividades, como el turismo. En efecto, la designa ción del área natural protegida como patrimonio de la humanidad fundada en principios de conservación de la naturaleza restringida, pone en el centro del desarrollo a la actividad turística de Península Valdés, particularmente el recurso turístico de la Ballena Franca Austral produciendo la invisibilización del patrimonio cultural (Curti, 2017) y los saberes esgrimid os por los pobladores:

«La pesca artesanal está en vías de extinción... siempre la mirada está más en el turismo, para las áreas protegidas, para la ballena...» (pescador, 21 de octubre de 2019, Radio LU17. Recuperado de https://lu17.com/tambien-es-noticia/la-pescaa rtesa nal-esta-en-via s-de-extinc ion).

Las actividades de pesca artesanal, turismo y ganadeńa en una misma expresión espacial conforman una imbricación de modeloseconómic os que discrepan desde su génesis, contraponiendo estructuras clásicas de explota c ión y privatiza c ión del teritorio -turismo y gana deńaversusuna tra dic ión de producción colaborativa en el marco de economías solidariasy bienes comunes-la pesca artesanal-. Un escenario de jerarquización del turismo por sobre el resto de las activida des a tenta contra las voca ciones del temitorio y debilita los procesos de construcción de la pesca artesanal como un bien intelectual (Vercelli y Thomas, 2008) que implique un 
mayor reconoc imiento. En efecto, la pesca artesanal despliega un conjunto de saberes loca les que exceden su utilidad económica y los modos de apropiación que permiten su circulación:

«as ideas, costumbres, tradiciones, saberes, creencias, lenguajes, formas de expresión, artes, técnicas, conocimientos o, genéricamente, todo a quello que se denomina cultura. Los bienes que tienen una calidad intelectual son abstra ctos, diná mic os y se encuentran distribuidos [o tienen la posibilidad de distribuirse ilimita damente] entre los integrantes de una comunidad» (Verc elli y Thomas, 2008).

En el Golfo San J osé y su borde costero hay, debido a su magnitud geográfica, diferentes zonas determina das por el PM. Se presentan zonas intangibles, zonas de uso sostenible restringido, zonas de uso sostenible, asentamientos poblacionales y zonas de rehabilitación natural y cultural. Cada una de las zonas está delimitada espacialmente tanto en el mar como en el espacio continental, y se deta lla lasactivida despemitidas: 1) en laszona sintangibles no está permitida ninguna actividad; 2 ) en las zonasde uso sostenibles restringido se permite la actividad de pesca artesanal (y en algunos puntos continenta les se permiten actividades tuŕsticas) ya que espreexistente al PM y presenta prá ctic asproduc tivasque no dañan ni modifican el sustrato marino; 3) en la zona de uso sostenible también se pemite la pesca artesanal mediante sustresartes de pesca, inclusive la maricultura de baja escala, y son lospuntosdonde se presenta una mayor cantidad de actividades tuństicas; 4) los asentamientos poblacionales permanentes se permiten solo en la comunidad pesquera de El Riacho, que también se la determinó como área de rehabilitación natural y cultural siendo que el a mbiente, sitios o elementos han sido alterados y deben ser sometidos a una estric ta rehabilita ción para su conservación (Plan de Manejo, 2001). El deterioro de losbancosnatura les de recursospesquerosen el intermareal de esta comunidad, y única fuente de subsistencia de lasfamilias, se vio fuertemente afectado por el impacto de visitantes que realizan la práctica de recolección sin pemiso ni c uida dospertinentes (entrevista personal, 23 de marzo del 2020). Helfrich (2008) ind ica que tiene lugar de manera paralela la pérdida de biodiversidad y de tradicionesculturales.

En otras playas como San Román, Bengoa, Fracasso, Larralde y Punta Gales el PM sólo permite el asentamiento temporario de pescadores, con infraestructura móvil operativa de a poyo a lasactivida desde pesca, ma ricultura artesanal y pesca deportiva. Esta regulación fue observada por pesca dores a rtesana les al momento de la confección del PM, advirtiendo que en ese entonces ya existían unida des habita cionales perma nentes de pesca dores desde hacía más de 30 años (pescador, entrevista personal, 24 de marzo del 2020).

\section{La pesca artesanal en búsqueda de regulación}

La pesca artesanal en Chubutesuna actividad productiva de baja escala que presenta un bajo impacto ambiental debido a las prácticas de captura selectiva y cumplimiento de recomendaciones téc nic as para el cuida do de los recursos. Es ta mbién el sustento económico de más de 100 familia ${ }^{8}$ y sus prácticas se transmiten de unos a otros, especia Imente

\footnotetext{
${ }^{8}$ Estimación realizada en el trabajo de campo.
} 
de padres a hijos o familiares 9 . Sus capturas son de bajo volumen, pero de un alto valor ec onómic o y social. La comercializa ción de sus productos se realiza en merc ados loc ales y nacionales, y contribuye ademása la dinamización socioeconómica de la comunidad local.

La comunidad pesquera artesanal ha tenido una partic ipa ción activa en experiencias de mesas de diálogo para la gestión de los recursos de la pesquería, que le ha permitido rea lizar una explotación más sustentable del recurso. La partic ipación a través de un espacio asociativo ha sentado un precedente para la elaboración de distintos dispositivos partic ipativos en los que las familias se han ga na do un espac io como interloc utores vá lidos frente al gobiemo local y provincial.

Las modalidades de pesca (figura 2) permiten alcanzar diferentes niveles de bienestar o seguridad ec onómic ${ }^{10}$. A pesar de sus distintas rea lida des, los pesca do res y sus familias se reconocen como parte de un sector con la identidad de la pesca artesanal a partir de un mundo de sentido compartid o basado en el saberhacerprofesional que implic a el conocimiento de lasartes de pesca, de las playas y suscaminos de acceso, de las prácticas que a seguran la sustenta bilida d en la explotac ión del recurso y que mantienen lazoscolabora tivos princ ipa Imente cuando están desempeñando sus labores en las playas operativas y en el mar. Aunque se han presenta do tensionesen los intentos de confomar proyectosintegrales para el sector, esta fortaleza ha pemitido consolidar expeniencias de colaboración que remiten a la conservación de saberesy recursoscomunes.

A mediados de la década del 90 la pesqueńa del Golfo San José sufrió el colapso de su principal recurso -la vieira tehuelche- y la pesqueńa fue vedada hasta el año 2000. A partir de esta situación los pescadores exigieron mayores medidas de manejo, y solicitaron la conformación de una mesa de manejo participativa. El gobiemo provincial comprendió la pertinencia del pedido y gestionó la conformación de la Mesa Técnic a Zona 1 (MTZ) donde los pesca dores no fueron considerados sólo como destinata rios, sino que co-diseña ron parte de las propuestas y compartieron saberes con investigadores y téc nic os del gobiemo ${ }^{11}$. La MTZ funcionó en el período 2001-2014 y fue en principio una conquista de una alianza conformada porpescadorese investigadores, sin embargo, se convirtió en un tipo de partic ipa ción otorgada por las autoridades, con momentos más propicios a decisiones vinc ula ntes, otros de carac tenístic as consultivas y hasta perío dos de intemup ción del funciona miento. Los resulta dos que se logra ron fueron signific a tivos para la actividad, la pesqueńa, la sustentabilidad de los recursosy repercutieron en toda la comunidad de pescadores, estableciénd ose normas formalese informales de buenas prácticas que se mantienen actualmente. Muchos de los ac uerdos quedaron forma liza dos en doc umentos téc nic os elaborados colaborativamente, otros tomaron mayor jerarquía conformando una batería de instrumentos nomativos de la actividad. El Documento Técnico $\mathrm{N}^{\circ} 9$ despliega la manera en que esa demanda se plasma en la Ley provincial de Pesca artesanal que reconoce

\footnotetext{
${ }^{9}$ Entendemos el entomo familiar en un sentido amplio incluyendo relaciones de vecindad.

${ }^{10}$ Cada arte de pesca es específica para un grupo de recursos, por ejemplo, peces o moluscos.
} 
tanto a la pesca artesanal como un bien a proteger como a las familias que tradicionalmente efectuaron la actividad a partir de un balance entre necesidades económicas y sociales y aprovec hamiento y desamollo sustentable. Si bien el documento pone de relieve lascuestionestéc nic as de la pesquería, el énfa sis en el marco legal da cuenta del carácter cívic o de la propuesta. No se trata de una legalidad meramente formal, sino que reconoce los princ ip ios susta ntivos a ntes menciona dosy el protagonismo de la asociación de pescadoresartesanales dota da de la responsabilidad y lascapacidades de autorregularla explotación de la pesca artesanal proponiendo su mayor protagonismo en el control del acceso al recurso.

\section{La pesca sin permiso}

Una de las reitera das demandas de lospesc a dores artesa na les consiste en limitar la presencia de pescadoressin permiso. A pesar de losavancesy acuerdosalcanzados, la pesca sin permiso sigue siendo un problema que se denuncia en toda oportunidad de encuentro con la autoridad de aplic ación estatal, en diálogo con técnicos, cuando son convocados en mesas instituc ionalesy también se ha expresa do en medios de comunicación (Revista Puerto, 2017, 2018). La dilatación y envergadura de esta situación genera conflic tos soc iotemitoria les y a mbientales que se desatan ante los vaivenes de disponibilidad de los recursos (Revista Puerto, 2016). Si bien los pescadores pemisionarios legales jerarquizan y practican las pautas de manejo sustentable y la nomativa vigente, al mismo tiempo las reconoc en débiles porque consideran que fallan los sistemas de monitoreo, control y fiscalización por parte de la autoridad de a plica ción. La a plic ación de la nomativa esconsiderada inefic az en la medida en que sólo alcanza a los pemisionarios.

Figura 2

Modalidades de pesca artesanal en Chubut

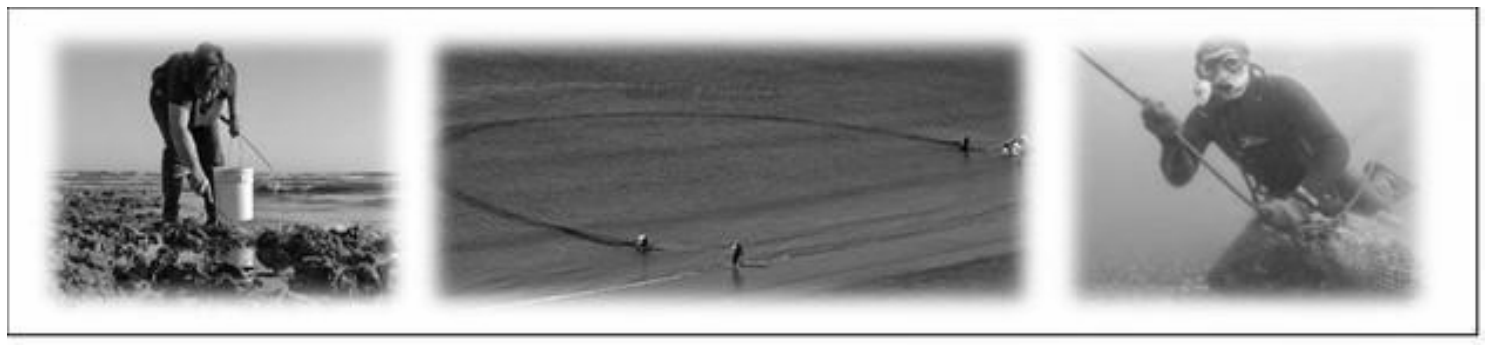

Fuente: Clúster de Pesca Artesanal y Maricultura de Península Valdés (2016)

E acceso a las playas, el cercamiento y los riesgos de privatización

Si bien la pesca artesanal en la provincia de Chubut se desempeña en tres golfos, para a na lizar la vincula ción de la actividad con los conceptos de bienes comunes, se considera la pesquería del Golfo San J osé desde dos dimensiones: 1) el acceso a las playas donde 
desa rollan sus a c tividades los pescadores rederos ${ }^{12} ; y, 2$ las pautas de manejo de la pesquería refinénd ose al cuerpo de agua y playasoperativa $\mathrm{s}^{13}$ de lospesc a dores ma risqueros ${ }^{14}$. El abordaje del conflic to del acceso a las playas se realiza a partir de estudios previos con métodos de mapeos colectivos elaborados por investiga dores locales y la comunidad de pescadores rederos. Por otro lado, para estudiar los aspectos de las reglas asociadas a la pesquería de mariscosse considera a Playa Larralde como un espacio representativo de la actividad ${ }^{15}$, ya que desde allí parten las embarcaciones hacia los puntos de pesca en las aguas del golfo, se realizan las maniobras y se asientan transitoria o permanentemente a lgunos pesc ad ores y sus fa milias.

Mediante el releva miento de campo realiza do en Playa Larra lde se pudo observarque hay presencia de prácticas no permitidaspor el PM en la zona de borde costero, como acampe tuństico, restos de leña quemada que señalan la utiliza ción de fuego, vehíc ulos de travesía, elementos de activida des a c uátic as no permitidas y edific a ciones que a la vista no presentan característic as de viviendas de pescadores ${ }^{16}$. Los visitantes, por desc onocimiento, circulan por bancos naturales removiendo sustrato y destruyendo la biodiversidad de zonas intangibles ${ }^{17}$. Según las estadísticas public adas por la Administradora de Península Valdés en el a ño 2017 se reg istra ron picos de 50.000 visita ntes mensua lesy en enero de 2018 supera ron los 83.000 ingresos $^{18}$.

El ingreso a Larralde está mediado por una tranquera que permanece abierta, indicando que hay un acuerdo con el dueño del campo lindero. Sin embargo, los propietarios de la estancia que es atravesada por el camino de ingreso, han realizado denuncias en los medios de comunic ación manifestando su disconformidad por nuevas edificaciones sobre la costa (Dia rio El Chubut, 2017). En respuesta, a lgunos pescadores rechazan que se trate de construcciones de fines de semana, sino que son «casas operativas para guardar herramientasy tener un espacio digno y cómodo para descansar» (Revista Puerto, 2017) ya que gran parte del esfuerzo pesquero se realiza en inviemo.

«Quienes vivimos de la pesca artesanal somos los más interesa dos en que nuestro entomo se mantenga saludable. Creemosque la opinión pública debe ser informada correctamente, y el sentido común indic a que esta es una playa operativa, histórica

\footnotetext{
${ }^{11}$ La MTZ se orientó a la resolución de problemas de la pesquería de mariscos del Golfo San J osé, aunque en las actas se observa el tratamiento de asuntos de recolectores de la comunidad pesquera de El Riacho y de rederos que operan tanto en el San José como en el Golfo Nuevo.

${ }_{12}$ Arte de pesca de costa, mediante la utilización de bote a remo para la captura de peces.

${ }_{13}$ Las playas operativas son los lugares que los pescadores han tomado de base para desamollar las maniobras de acceso al mar. Allí están sus embarcaciones, tractores, casillas o pequeñas unidades habitacionales donde pasan el día de trabajo, la temporada de pesca e incluso, algunos viven allí.

${ }^{14}$ Arte de pesca selectiva de marisquería por buceo.

${ }^{15}$ Es la playa operativa de marisqueros más cercana a la ciudad de Puerto Madryn. En el Golfo San J osé hay cuatro playas operativas: Lamalde, Fracasso, El Riacho y Bengoa.

${ }^{16}$ Las viviendas de pescadores se caracterizan por tener en su cercanía numerosos elementos para las labores de pesca: embarcaciones, tractores, redes, cajones, entre otros.

17 En la comunidad de El Riacho los bancos naturales de mejillón y pulpito están en peligro de extinción.

18 http s:// peninsula va ld es.org .a r/ blog/2018/02/02/ma s-d e-83-mil-perso na s-visita ro n-peninsula-va ld es-en-elmes-de-enero/
} 
para nuestra privilegiada marisquería, merece mejorar mucho más toda vía... dejando atrás la imagen de marginalidad que siempre se pretendió asociar a nuestra actividad. Una injusta imagen porque siempre tuvimos la aspiración de mostrara nuestra pesca artesa nal en cond ic ionesde ma yor dignidad »(pescador, Diario El Chubut, 2017).

Desde La rra lde no se observan inc umplimientos en relación a las a ctivida des no permitidas en el cuerpo de agua en función de la sostenibilidad de los ecosistemas marinos ${ }^{19}$. Sin embargo, los registros periodísticos dan cuenta de las prácticas de furtivismo desplegadas desde otras playas (Diario J omada, 2017; El Diario de Madryn, 2018). En tal sentido la demanda de control en favor de la sustentabilidad de la actividad sigue vigente y esrecordada en los distintos espacios de trabajo con las autoridades donde el control de la pesca furtiva es un rec lamo insistente.

Sobre la accesibilidad a las playas operativas que se utilizan para desempeñar el arte de pesca de redeńa, los rederos necesitan llegar por distintos puntos a cada playa operativa, a tra vés de lo que ellos denomina n bajadas (Marín et al., 2017). Se presentan situa ciones en el teritorio que generan la restric ción del acceso a lasplayas-en a lgunoscasosdesde hace décadas- pormotivosque incluyen el cierre de loscaminos de acceso porparte de propietarios de establecimientos rura les, la instalación de emprendimientos turísticos, la falta de mantenimiento de loscaminos porparte del Estado, y la creación de áreas protegidas que restringen el a cceso a a lgunossectoresc osteros (Ma ńn et al., 2017). Estosconflictosencontraron un cauce de soluciones parcia lesa tra vés de consensos con el Estado provincial, donde se acordó el acceso a 19 playas a través de tranqueras habilitadas para los pescadores (Diario Jomada, 2015), sin embargo no se ha cumplido con la meta (Mańn et al., 2017).

\section{E clúster de pesca artesanal y maricultura Península Valdés. Una experiencia trunca}

La crea ción delc lústerPAyMPV respondió a una decisión del gobiemo de la provincia de Chubut de participar en el programa de apoyo a las economías regionales mediante la adhesión al programa de crédito del Banco Interameric ano de Desa rollo (BID). Se considera un sectorcon potencial debido a que cuenta con una trayectoria de organización, con distintos proyectos para el sectory el acompaña miento de institucionesc ientífic o-tec nológic as. Adoptarla «metodología c lúster»tal como lo sintetizan distintos téc nic os, implica que el clúster no sea «una lista de demandass sino elaborar un proyecto consensuado para y con el sector ${ }^{20}$.

Según la coordinación el cluster vino a «omaliza r» los intercambios que existía n de manera previa entre las asociaciones de pesca dores artesanales y distintas instituciones académicas (CENPAT, UTN, etc.). La decisión de las autoridades provinciales de incluir al sector de pesca

\footnotetext{
19 Se utilizó la técnica de cuenca visual (Femández Vítora, 1996) desde un punto elevado en playa La rralde. ${ }^{20}$ Se define como un conjunto de empresas e instituciones públicas y privadas con proximidad geográfica, que participan de «un área de negocios específico» y comparten una base común de factores. Dicha metodología define funciones para cada actor involucrado y etapas pautadas para la definición de proyectos cuya finalidad última es lograr instalar un espacio de decisión de políticas sectoriales con la participación de los productores.
} 
artesanal y maricultura en el programa de apoyo a los clúster y microrregiones implicó una novedad que lostéc nic osy pescadoresno dejaron de señalar, mostrando que las dific ultades que encuentra el sector se deben a la escasa regulación o al incumplimiento de lasnomativas.

El C lúster de PAyMPV c ontó con distintas instancias de funciona miento en las que esta ban representadospescad oresa rtesa na les, representa ntes del mundo a so c iativo junto con técnic os de instituciones científic o-tec nológ ic as y a utorida des provincia les y na ciona les de regulación de la actividad de pesca, su comercializa ción o procesamiento.

Un señala miento partic ular surge de la contribución a tribuida a los productores: consiste en la «participación en el proceso de formulación de PMC», el documento final que debía proponer un proyecto de desarrollo para el sector. Es decirque a lo largo de todo el proceso su presencia proveyó la justificación de los esfuerzos realizados y como garantía del interés del sector priva do en llevar a cabo los proyec tos formula dos. Este argumento a parece también en diversas actasy documentos de trabajo que dan cuenta del reconocimiento obtenido por este grupo profesional como agentes activos de los procesos que los involucran.

El clúster se vio absorbido por la necesidad de dar respuesta a situa ciones de gestión de la pesqueńa, el acceso de lospescadoresa lasplayasy la falta de controlesfrente a la pesca furtiva que produce competencia desleal frente a los estándares que deben observar los pesc a dores permisiona rios -las exigencias refieren tanto a las condic iones de las embarcaciones como a los procedimientos para el desa rollo de la actividad-que renuevan anualmente sus permisos. Estas demandas se impusieron en la agenda prevista por la metodología del c lúster retrasando la rea liza ción de los enc uentros públic os lla ma dos foros III y IV. A su vez, el cambio de gestión en diciembre de 2015 fue un momento de incertidumbre en el proceso de constitución del clúster. La elecc ión de nuevas autorida desna ciona les y provinciales implicó un paréntesis en la construc ción del clúster, su evaluación por parte de las nuevas autoridades y la decisión de continuar o no con un proceso participativo en el ámbito de la pesquería, y posteriomente su aceleración para dar cumplimiento con el calendario establecido por los tiempos del BID. La necesidad de responder al calendario BID pareció «traccionar»-para retomar el término utilizado por algunos facilitadores- el avance de la formulación de las distintas etapas, pero las distintas tensiones latentes -que circula ban en rumores de pa sillo- emergieron en el Foro IV, el momento en el que se debían priorizar los proyectos que se iban a tener en cuenta para completar la formulación del plan de mejoras competitivas y a signar el presupuesto. La tensión entre la constitución de un proyecto común y la sumatoria de proyectosporarte de pesca se hizo presente.

En el transc urso del Foro IV se decidió que cada aso cia c ión trabaja ra losproyectosexistentesen mesa sc on distintos téc nic osy losfuera priorizando. La disc usión es detalla da, cua ndo hizo falta los técnicos trajeron a la mesa el argumento de la aplicación del PM, ajustando los aspectos téc nic osa esa noma. Másallá de lasreservasexistentessobre el uso de ese instrumento, parece ejercerun poderde veto sobre losa spectos téc nic os de losproyectos. Sin embargo, se expresa que esasrestric c iones pueden reformularse siguiendo losa cuerd os de la sa utorida desprovincia- 
les. Algunos criterios por los que se prioniza ron los proyectos dan cuenta de lasmaneras en que se concibió al clúster. Entre los argumentos esgrimidos se tiene en cuenta que un proyecto «beneficia a todos», que «se puede realizar en un año», que «aprovecha los recursos de las asociaciones», «que surgen del sector priva do». En la mesa de la asociación se consultaba a los técnic os sobre el grado de autonomía respecto del uso de los recursosy bienesa adquirir.

Sin embargo, un proyecto de maricultura introducido en la última etapa generó muchos cuestionamientos. El proyec to fue desa rolla d o y presenta do por un técnic o de la Secretaría de Pesca Provincial. Losbuzosmanisqueros se mostraron dispuestosa sumarse al proyecto, que representaba mayor diversifica ción frente a la reducción de los bancos naturales. Sin embargo, los pescad ores de las resta ntesartes de pesca fueron retic entes, no se sentían incluidosen un proyecto que absorbeńa gran parte de la financiación posible. Lospescadores en general conocen a lostéc nic os provincialesque trabajan con el sector y pensaban adaptacionesteniendo en cuenta lasdudasplanteadas. Sin embargo, la desconfianza era persistente frente a lasnuevas a utoridadesprovincialesque desconocían la actividad y no habían participado del proceso ${ }^{21}$.

Entre la presentación de cada proyecto los técnic os universitarios intentaban ordenar la disc usión recordando los procedimientos propios del clúster o pidiendo a la coordinación que los recuerde. Estas intervenciones podían ser objeto de crítica o desaprobación de parte de los pescadores y la coordina ción recordaba que los pescadores son los que deciden. En una segunda etapa, de ejecución de los proyectos, el clúster debía adoptar una forma juńdic a propia que le permitiera dejar de funcionar como una suma de instituciones. Esta fase fue demorada, primero por la dific ultad de obtener el acuerdo del BID, luego por razones presupuestarias, finalmente fue desactivado.

\section{Figura 3}

\section{Complejidad de la gestión temitorial}

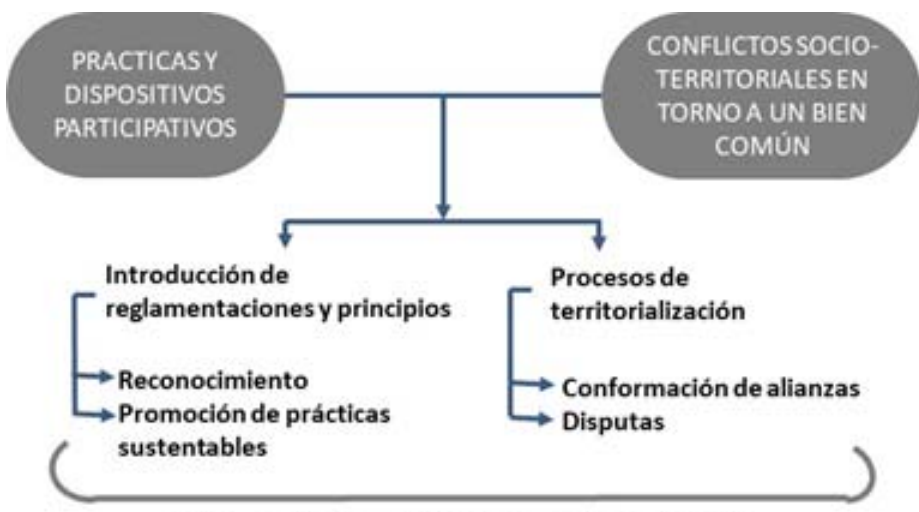

Conformación de un régimen de acción territorial

Fuente: elaboración propia

\footnotetext{
${ }^{21}$ Un facilitador enviado por las autoridades nacionales al foro IV, señaló que la conflictividad suele emerger en esta instancia en donde puede hacerse evidente la persistencia de cierta desconfianza entre algunos actores del clúster.
} 
La figura 3 muestra la complejidad de la gestión territorial donde la formula ción e incorporación de nomativa no es lineal, y requiere para su puesta en vigencia la participación a c tiva de los a ctores involucrados. Los principios involuc rados en las insta ncias de debate involucran tanto aspectos de orden científico técnico, como a la familiaridad de las interacciones entre los distintos sec tores como al marco legal en que se inscriben.

\section{Discusión}

Los distintos dispositivos instituciona les aportan diversos elementos que dan cuenta de la complejidad del manejo de la pesquería artesanal en un teritorio que aparece en disputa con otras a ctivida des ec onómic as, soc ia les y cultura les. Es dec ir, a sistimos a un proc eso de teritoria liza ción, un proceso de domina ción y control de un espacio específico a tra vés de instituc iona liza r a c tos y sa beres, gracias a los cuales el Esta do desa rolla una rela ción entre la población y el espa cio geográfic o. En particular, en un sistema de co-ma nejo son imprescindiblesta nto el apoyo instituc ional como el desa rollo comunita rio. «Éste es entendido en tanto proceso de promoción de saberes que generen capacidades autogestivas. De este modo, se a punta a lograrque el sistema sea sustentable, no sólo en un sentido económic o, sino social y cultural» (Uruburu, 2014, p. 64).

El teritorio definido como Área Natural Protegida Península Valdés es preservado en ta nto bien y patrimonio de la humanidad donde confluyen distinta s a c tivida des económicas (turismo, pesca artesa nal, ga na dería) y distinta s visiones de la gestión a mbiental y la conservac ión. Estas diferencias se crista liza n en los usos restring id os y permitid os del temitorio. Las dinámicas de procesos participa tivos, tal como se ma nifiestan en el ámbito económico, con las tensiones que resultan de la heterogeneidad entre los mismos pesc a dores, su a ntigüedad en la actividad, sus rela ciones con las a utorida des y su proyección hacia el futuro ya que no solo está en juego la rentabilidad presente de la actividad sino también la sustentabilidad de los recursos. Los rec la mos persistentes de los pescadores artesana les muestran la tensión entre legalidad y legitimidad conferida al marco legal. La legalidad da cuenta de los compromisos del Esta do en relación a ese temitorio y las personas que lo habitan, así como del reconocimiento jurídico y político de los a gentes habilita dos para intervenir. Las mesas instituciona les tienen un gra do a lto de formalidad (presencia del Estado, actas, etc), sin embargo, en los dispositivos observados el lenguaje de derechoseslimitado, a parece como un lenguaje técnico sobre los usos permitidos en el PM. En ocasionesesevoca do en forma elíptic a señalando que una actividad «no está permitida en la nomativa»pero sin establecer precisamente la documentación referida. Su eficacia escuestionada, como se dijo, debido a la persistencia de la pesca informal y en general a la falta de presencia de agentes públicos que hagan efectivo su cumplimiento en el teritorio. El proceso participa tivo se agota en la fo mula ción desplazando a los pesca dores artesa nales y otros participa ntes al momento de su puesta en marcha. La propuesta de «contrato vinculante entre todos los a ctores»(Ostrom, 1999) no parece obligara cumplir con los acuerdosiniciales como lo mues- 
tra el reclamo porla revisión del PM que su promulga ción en 2001 señalaba cada cinco años.

Las documentaciones lega lesson invoca das para regular la pla nific ación de proyectos de desarrollo de la actividad pesquera y la maricultura. Lo mismo sucede con los criterios téc nic os, que tienen en cuenta lascaracterísticas de la pesqueńa y saberesdetentadospor lospropios pescadoreso lasvaloraciones sobre la equidad de determina das medidas, que alcanzan al conjunto de lasartesde pesca. La forma de ocupación del teritorio imumpe en el espa cio público mostrando la tensión existente con los usos de la ganadería y el turismo, o más precisamente con los usos costeros en los cua les la sexplota ciones priva das son vecinas colindantes con la costa. El llamado de alerta sobre los peligros de extinción de la pesca artesanal en las futuras generaciones invoca a la actividad económica y los modos de vida digna desarrollados en tomo a la pesquería y su transmisión intergeneracional. El reconocimiento de las tradiciones orales, la preocupación por la pemanencia a lo largo del tiempo señala dimensiones de la polis tra dicional que conviven con la ciudad cívica, basada en el bien común, la solidaridad y la equidad.

\section{Conclusión}

El a ná lisis permite señalar que la pesc a artesanal como bien público evoca a los principios familia res tanto como a los principios de bien común que se oponen a la mirada mercantilista de los recursos e individualista de la propiedad, incorporando principios que limitan los modos de explotación de la naturaleza. La crítica elevada hacia los incumplimientos nomativos, hacia las formas de trabajo excesivamente precarias o hacia el desconocimiento de las tradiciones pesqueras frente a la explotación turística dan cuenta de una forma de definición de lo común que alcanza sufic iente reconocimiento para establecer buenas prácticas y marcos nomativos acordes, pero no logra imponerse frente al avance de formas de privatización del temitorio. Se trata de un proceso a bierto en el cual la valoración de los bienes de la natura leza como bienescomunes permite el desa rollo de subjetividades que reivindiquen la equidad, la economía social y solidaria para pensar la defensa de lo común frente al avance de diferentesfomas de despojo social y ambiental.

\section{Agradecimientos}

La investigación se encuadra en un proyecto sobre procesos de institucionalización de organiza ciones de la sociedad civil (FCE-UNPSJ B RCS 328/18) y en el trabajo de investiga ción para la tesis doctoral en Ordenamiento Temitorial de Lorena Alvarez Manriquezasí como su trabajo de Maestría en Desa rrollo Teritorial. 


\section{Referencias}

Álva rez Manníquez, L. (2018). Usos del espacio marino-costero en Playa Larralde, Golfo San José, Península de Valdés. Argentina. Informe Técnico. Puerto Madryn: Grupo de investigación y desarrollo de Tecnologías Acuícolas y Pesqueras -GIDTAP- Universidad Tecnológic a Nacional.

Bollier, D. (2008). Los bienes comunes: un sector soslayado de la creación de riqueza. Pp. 30-41 en S. Helfrich Genes, bytes y emisiones: Bienes comunes y ciudadanía. Ciuada de México, Méxic o: Ediciones Böll.

Boltanski, L. (1990). «Sociologie critique et sociologie de la critique» en Politix, 10 (11), 124-134.

Bolta nski, L. y Thévenot, L. (1991). De la J ustific a tion. Leséconomies de la grandeur. Paris, France : Gallimard.

Boltanski, L. (2000). El amor y la justicia como competencias. Tres ensayos de sociología de la acción. Buenos Aires, Argentina. Editorial Amorrortu.

Ca illé, A. (2007). So c iology a s Anti-Utilita ria nism. Europea $\mathrm{J}$ o uma I of So c ial Theory, 10(2), 277-286. doi: https://doi.org/10.1177/1368431007078893

Coraggio, J .L (2011). Ec onomía Soc ial y Solidaria. Q uito, Ec ua dor: Ed ic ionesAbyaYala.

Curti, L. (2015). Construc ciones Sociales del Patrimonio Histónico e Identitario de Puerto Pirámides en Conocimiento, Paisaje, Temitorio. Procesos de cambio ind ividual y colec tivo, Río Gallegos, Argentina: UNPA, CIGA, UNRN.

Gómez Orea, D. (2002). Órdenación territorial. Madrid, España. Coediciòn Ediciones Mundi-Prensa y Editorial Agrìcola Española S.A.

Guery, A. (2003). Institution. Histo ire d'une notion et de ses utilisa tions da ns l'histo ire a vant les institutionnalismes', Cahiers d'éc onomie politique, 1 (44), 7-18.

Gusfield, J. (2016). La sociología de los problemas públicos. Buenos Aires, Argentina: Siglo XXI.

Helfrich, S. y Haas, J. (2008). Genes, bites y emisiones: Acerca del significa do estratégico del debate de los bienes comunes, pp. 311-28. En S. Helfrich Genes, bytes y emisiones: bienes comunes y ciudadanía. Ciudad de México, México: Edic iones Böll.

Mathieu, L. (2011). Marcos y ciudades: del orden del discurso a la acción en situación, Disc urso y Acción, 6 (11), 33-58.

Nardacc chione, G. (2003). Sobre la deliberación en público: entre la argumentación y la negociación - Post Data, 9, 125-140.

Lafuente, A. (2008). Los cuatro entomos de los bienes comunes, pp. 63-67. En S. Helfrich Genes, bytes y emisiones: bienes comunes y ciudadanía. Ciudad de México, México: Ediciones Böll.

Lerch, A. (2008). La tragedia de la «Tragedy of the commons, pp. 115-26 En S. Helfrich Genes, bytes y emisiones: bienes comunes y ciudadanía. Ciudad de México, México: Edic iones Böll.

Marin, F., Cinti, A., Dell'Arciprete, P., Ca rreño, G., y De Francesco, E. (2017). Pla yas y bajadas usadas por los rederos de costa de la Zona 1 de Pesca Artesanal, Provincia de Chubut: Una colaboración entre científic osy pescadores. Informe Técnico. Puerto Madryn: CESIMAR CCTCenpat CONICET.

Ostrom, E. (2002). Chapter 24 Common-pool resources and institutions: Toward a revised theory. Vol. 2.

Ostrom, E. (2007). A diagnostic approach for going beyond panaceas. Proceedings of the National Academy of Sciences of the United States of America 104(39)15181-15187.

Ostrom, E. (2009). A general framework for a nalyzing sustainability of socialecological systems. Science 325(5939)419-22.

Ostrom, E., Burger, J., Field, C. B, Norgaard, R. B. y Policansky, D. (1999). Revisiting the commons: Local lessons, global challenges. Science 284(5412) 278-82.

Patta roni, L. (2007). La ville plurielle. Quand les squatters ébranlent l'ordre urbain. In M. Bassand, V. Kaufman et D. Joye (dir.), Enjeux de la sociologie urbaine. Lausanne, France: PUR

Plan de Manejo de Península Valdés. (2001). Provincia de Chubut. https:// peninsula valdes.org.ar/desca rgas/

Rius, P. (2018). Reflexiones sobre la economía social a partir de espacios 
partic ipativos. El caso del cluster de pesca artesanal V J omadas de Investigación en Ciencias Sociales FHCS-UNPSJ B, Comodoro Rivadavia.

Schultz, Al. (1993). La construcción signific ativa del mundo social. Buenos Aires, Argentina: Paidós.

Santa Ana, C. (2004). Los derechos de uso temitorial (DUTS) como altema tiva para el manejo sustentable de recursos pesqueros: El caso de la comunidad de recolectores de costa de El Riacho (Golfo San J osé, Argentina). Grado, Universidad de la Patagonia San Juan Bosco. Facultad de Ciencias Naturales, Puerto Madryn.

Sva mpa, M. (2011). Extra c tivismo Neodesa rollista y movimiento so c ia les. ¿Un giro ecotemitorial hacia nuevas altemativas? En: M. Lang y D. Mokrani (comp.) Más allá del desarrollo. Grupo Permanente de Trabajo sobre Altemativas al Desarrollo, pp. 185-216.Quito, Ec ua dor: Edic iones Abya Yala- Fundación Rosa Luxemburgo

Thévenot, L. (2016). La acción social en plural. Buenos Aires, Argentina: Siglo XXI.

Touney, V. (2011). Soc iologie des Institutions. Paris, France: PUF

Uriburu Blas, A. (2014). Conflic tos socioambientales. Una experiencia de gestión comunitaria de recursos naturales, Cuademos de Antropología, (11), 57-68.

Vercelli, A., y Thomas, H. (2008). Repensando los bienes comunes: a nálisis sociotéc nico sobre la construcción y regula ción de los bienes comunes. Scientiae Studia 6(3)427-42.

Vollan, B., y Ostrom, E. (2010). Cooperation and the commons. Science 330(6006)923-924.

\section{Fuentes periodísticas}

Diario El Chubut. (2017). Denuncian construcciones ilegales en Playa La rra lde. Recuperado 26 de junio de 2020 (https://www.elchubut.com.ar/nota/201712-3-22-3-57-d enuncia n-c onstruc c iones-ilega les-en-pla ya-la rra lde/a mp).

Diario J omada. (2015). Provincia y pescadores ordenaron la actividad en El Doradillo. Diario Jornada. Recuperado 28 de junio de 2020 (https:// ww w.diariojornada.com.ar/117034/so ciedad/provincia y_pescadores_artesanales_ordenaron_la_actividad_en_el_doradillo/).

Diario Jomada. (2017). Awstin a segeguró que se combate lā pescā furtiva en Playa Bengoa. Diario Jornada. Recuperado 26 de junio de 2020 (https:// www.dia riojornada.com.ar/ 182062/provincia / a wstin_a seguro _ que_se_combate_la_pesca_furtiva_en_playa_bengoa/).

El Diario de-Madryn. (2018). De comisaron mariscos provenientes de la pesca artesanal irregular. El Diario. Recuperado 26 de junio de 2020 (https:// www.eld ia rioweb.com/2018/08/ decomisa ron-ma risc os-provenientes-de-lapesca-a rtesanal-irregula r/).

Revista Puerto. (2016). Pescadores artesanales vuelven a reclamar controles. revista puerto. Recuperado 26 de junio de 2020 (https://revistapuerto.com.arl 2016/03/ pesc a d ores-a rtesa na les-vuelven-a -rec la ma r-c ontroles/).

Revista Puerto. (2017). Artesanales niegan ser usurpadores en Península Valdés. revista puerto. Rec upera do 26 de junio de 2020 (https:/ / revista puerto.com.ar/ 2017/12/a rtesa na les-niega n-ser-usurpa do res-en-peninsula -va ld es/ ).

Revista Puerto. (2018). Fuerte reclamo de artesanales al Gobiemo de Chubut. revista puerto. Rec upera do 26 de junio de 2020 (https:/ / revista puerto.com.ar/ 2018/04/fuerte-rec la mo-d e-artesa na les-a l-gobiemo-de-chubut/). 